\title{
PECULIARITIES OF NANOMODIFIED PORTLAND SYSTEMS STRUCTURE FORMATION
}

\author{
Uliana Marushchak ${ }^{1}$, Myroslav Sanytsky $^{1}$, Oksana Pozniak $^{1}{ }^{凶}$, Oksana Mazurak $^{2}$
}

https://doi.org/10.23939/chcht13.04.510

\begin{abstract}
Regulation of hydration processes on nanostructure scale due to the competition adsorption modifying of hydration products by polycarboxylate and adding of nanosized C-S-H nuclei allows promoting homogeneous distribution of solid phase in the structure of cement paste on the micro- and nanolevel, provides the growth of contact amount between hydrates, results rapid structure formation and strength synthesis of Portland cement system.
\end{abstract}

Keywords: nanomodification, Portland cement, polycarboxylate superplastisizer, hydration, adsorption modifying, portlandite.

\section{Introduction}

Evolving of innovative concrete materials with specified properties and durability is possible through a nanotechnology-based innovative processing of Portland cement [1]. Nanotechnology and nanoscience are creating new possibilities to control and improve construction materials used for civil infrastructure applications [2]. Promotion of fundamental multiscale models for concrete is possible through advanced characterization and modeling of concrete at the nano-, micro-, meso-, and macroscales. Such scientific approach is based on the usage of nanoparticles potential $(1-100) \cdot 10^{-9} \mathrm{~m}$, which is defined by the size effect and is spread within the range of 1-100 atom-molecular diameters. As the particles become nano-sized the proportion of atoms on the surface increases relative to those inside; this leads to "nanoeffects" and changes the properties of the material to a great extent to produce material with novel and smart properties [3,4].

Currently, the most dynamic research area in terms of nanotechnology concerned with cement and concrete is

\footnotetext{
${ }^{1}$ Lviv Polytechnic National University

12, Bandery St., 79013 Lviv, Ukraine

${ }^{2}$ Lviv National Agrarian University

1, V.Velykogo St., 30831 Dubliany, Lviv region, Ukraine pozniak@ukr.net

(c) Marushchak U., Sanytsky M., Pozniak O., Mazurak O., 2019
}

the understanding of the Portland cement hydration mechanism and the use of nano-size ingredients. [5]. In this case, the trend to modify and optimize cementitious binders by means of nanotechnology and nanoscale additives continuously increases. The following modificators of cement structure are used: nanoscale fillers, supramolecular additives and functional nanoadditives, which influence hydration and/or structure development.

The first strategy of building materials nanomodification is implemented when introducing energetically active ultrafine mineral additives, the nanoparticles of which are characterized by high uncompensated surface energy [6]. These nanoparticles are capable of significant change in physico-chemical interactions in concrete, playing the role of catalysts or crystallization centers, depending on concentration and the chemical composition of the surface. Typical examples for these fillers are micro-silica, nanoscale pyrogenic $\mathrm{SiO}_{2}, \mathrm{TiO}_{2}$, $\mathrm{Al}_{2} \mathrm{O}_{3}, \mathrm{Fe}_{2} \mathrm{O}_{3}, \mathrm{CaCO}_{3}$ and other particles [7-10]. Their main task is to optimize the grain size distribution leading to a highly filled and compact cement matrix with reduced pores and voids. The effect of the filler in the initial period and the early Pozzolan reaction is provided by the formation of nanoscale $\mathrm{CSH}_{-}, \mathrm{AF}_{\mathrm{t}^{-}}$and $\mathrm{AF}_{\mathrm{m}}$-phases in the case of using silicon and aluminum-containing additives [11-13]. At the same time, it should be noted that ultra- and nano-dispersed mineral additives are characterized by high dispersion, which causes the growth of water demand and reduced mobility of concrete mixtures.

One of the widely used nanotechnology techniques in the production of concrete and solutions is the modification of surfactants [5, 14]. Supramolecular additives for cement and concrete can act as high performance dispersants, rheology modifier and known as a plasticizer. They modify and partially cover the surfaces both of the starting materials as well as of the forming hydrate particles. They also lower the surface energy, control rheological properties of the cement paste by electrostatic, hydrophobic or steric interactions [15]. Typical supramolecular additives usually have sulfonate, carboxylate or amine groups. All of them act in the liquid pore solution before the final hardening of the concrete. The effect of such modifiers is observed in the change in 
chemical processes on the phase interface due to the creation of adsorption layers which restrain the growth of crystals, affect their habit, the degree of wetting of dispersed particles, and reduce the rate of hydration of Portland cement $[14,16]$.

A new generation of superplasticizers based on polycarboxylate ether (PCE) graft-polymers with nanodesigned chains consists of anionic backbone (with carboxylate groups) and nonionic (polyglycol) side chains. Such superplasticizers provide a mechanism of action that greatly improves the effectiveness of cement dispersion and allow to increase the strength due to essential decrease of water-to-cement ratio [17]. Alongside the electrostatic effect of the PCE backbone, the long side chains linked to the backbone generates an additional effect based on steric hindrance that provides a physical barrier, which increases the cement particles ability to separate and disperse. The steric hindrance plays a dominant role compared to electric repulsion in the dispersion of cement paste by PCE [15].

The latest means of nanomodification of cementitious systems are functional nanoadditives which influence hydration and/or structure development. Such systems comprise nanotubes (mainly carbon nanotubes) [18, 19], nanoscale C-S-H particles [20]. Modifying effects and effect of introduced nanomaterials mechanism on the hydration peculiarities and properties of cement are realized in the so called seeding effect, packing effect, internal reinforcement, increased chemical activity. Owing to mentioned effects the gain in early strength of Portland cement is accelerated $[11,21]$.

The main task of development of high performance cement systems focuses on the manipulation of the hydration process of cement by nanomodification of the nucleation period of those materials. When introducing chemical compounds of various nature into the cement system the reaction to the action of these substances and change in the hydration conditions is taking place [22-24]. Nanoengineering and nanomodification of cementitious materials can be done between their dissolution and hardening. Especially the nucleation step and the crystal- lization period are most suitable to change the material properties by adding active supramolecular components or colloidal nanoseeding additives [17].

In this regard, the actual task is to study the complex nanotechnological approach for organizing the structure and formation of Portland cement properties by introducing a polycarboxylate superplasticizer and nano-sized $\mathrm{C}-\mathrm{S}-\mathrm{H}$ nuclei. It is important to establish the influence of polycarboxylate superplasticizers, as well as nanosized calcium hydrosilicates on the processes of structure formation and crystallization in the cementing matrix.

\section{Experimental}

\subsection{Materials}

Portland cement CEM I 42.5R (PJSC "IvanoFrankivskcement", Ukraine) produced according to EN 197-1 was used for the experiments. To increase the efficiency and provide necessary properties of the cement systems the superplastisizer based on polycarboxylate esters (PCE) was used as a modifier and suspended synthetic nano-sized $\mathrm{C}-\mathrm{S}-\mathrm{H}$ nuclei as a hardening accelerator (Master X-SEED 100).

Admixture Master Glenium Ace 430 (BASF) with nanodisigned chains in form of light brown viscous liquid (density $1.06 \pm 0.02 \mathrm{~g} / \mathrm{cm}^{3} ; \mathrm{pH}=5.5 \pm 1.5$; solid content $25 \pm 1.25 \%$ ) was used as polycarboxylate-type superplasticizer. The molecular weight of PCE is about 7000. Infrared spectra of PCE are depicted in Fig. 1. The analysis result of spectra is as follows: $\mathrm{O}-\mathrm{H}$ of alcohol stretching, vibration bond at $3700-3300 \mathrm{~cm}^{-1}$; the signals at $2870,1460 \mathrm{~cm}^{-1}$ are attributed to $-\mathrm{CH}_{3}$ and $-\mathrm{CH}_{2}-$, absorption peak at $1720 \mathrm{~cm}^{-1}$ proves the existence of ester bond; the peaks at around $1150 \mathrm{~cm}^{-1}$ prove that it contains the side chain of polyethylene glycol methyl ether in the molecular structure. Also, the signals at 1460 and $1354 \mathrm{~cm}^{-1}$ are the characteristic absorptions of polyethylene oxide (PEO)-group, the bond at $615 \mathrm{~cm}^{-1}$ is typical of $\mathrm{C}-\mathrm{S}$ stretching vibration.

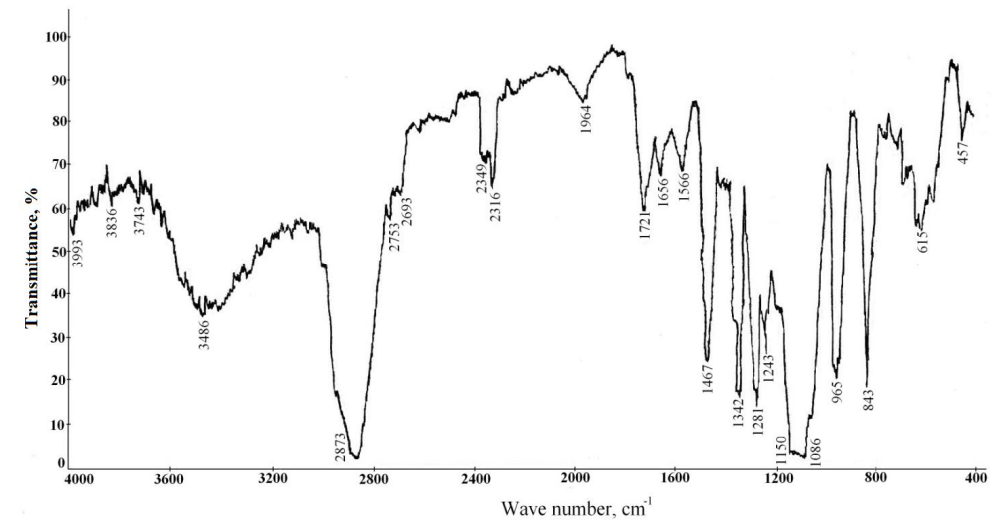

Fig. 1. IR-spectrum of polycarboxylate superplastisizer 
The admixture Master X-SEED 100 (BASF) is a white suspension containing nanoparticles (density $1.13 \pm 0.03 \mathrm{~g} / \mathrm{cm}^{3} ; \mathrm{pH}=11 \pm 1$ ).

The raw materials used for the synthesis of portlandite crystals were analytical grade potassium hydroxide and calcium chloride bihydrate. They were used for separately prepared saturated solutions in $\mathrm{CO}_{2}$-free distilled water.

\subsection{Methods and Procedure}

The investigation of PCE-addtives influence on the surface strain of water was carried out by the method of ring tearing off. The $\xi$-potential of cement suspensions $(\mathrm{W} / \mathrm{C}=5.0)$ with PCE and without any admixtures was determined by an electrophoreting method of movable border.

The portlandite crystals were grown in the medium of water and admixtures (polycarboxylate-type superplasticizer and X-SEED) by the counter-diffusing method. Two beakers of different diameters and heights were taken; the smaller beaker was inserted inside a bigger one. $\mathrm{CO}_{2}$-free water was added to a depth just above the rim of the inner beaker. The potassium hydroxide saturated solution was delivered to the bottom of the inner beaker with a pipette. The calcium chloride solution was then added outside the smaller beaker. The bigger beaker was covered with an inverted Petri dish and the reagents are allowed to diffuse slowly through the liquid.

The phase identification of the obtained $\mathrm{Ca}(\mathrm{OH})_{2}$ crystals was made by X-ray powder diffraction. The portlandite crystal morphologies were analyzed by a scanning electron microscopy (SEM).

The evaluation of the properties of nanomodified Portland cement systems was carried out through setting and compressive strength tests. Consistence of cement paste based on nanomodified cementitious systems and period of setting were determined according to EN 196$3: 2005$. To determine the strength of cement paste we prepared cube-shaped samples $(2 \times 2 \times 2 \mathrm{~cm})$. The formed samples were hardened under normal conditions (temperature $293 \pm 2 \mathrm{~K}$, relative humidity $95 \pm 5 \%$ ) and tested after $6,8,12,18,24$ and $48 \mathrm{~h}$, as well as after 7 and 28 days.

\section{Results and Discussion}

One of the most important characteristics of surfactants is their surface activity, which determines the adsorption capacity of the surfactant and characterizes the force that holds the substance on the surface, relative to a value of the Gibbs adsorption [25]:

$$
g=-(\partial \sigma / \partial c)=R T(\Gamma / C)
$$

where $R, T, \Gamma, C$ - universal gas constant, temperature, Gibbs adsorption and concentration, respectively.

In order to determine the surface activity of polycarboxylate esters, the surface tension of their aqueous solutions of different concentrations $\sigma=f(c)$ was studied (Fig. 2). The introduction of polycarboxylate provides a reduction of water surface tension from 72.6 to $63.1 \mathrm{~mJ} / \mathrm{m}^{2}$. In this case, the surface activity is:

$$
g=-\operatorname{tg} \alpha=5.9 \cdot 10^{-3} / 0.65 \cdot 10^{-2}=0.9 \mathrm{~J} \cdot \mathrm{m} / \mathrm{mol}=0.9 \cdot 10^{9} \mathrm{G}
$$

Analysis of the surface tension of polycarboxylates-based surfactants shows that they are characterized by a significant surface activity compared with traditional surfactants $\left(g=10^{7} \mathrm{G}\right)$ at a lower concentration [25].

The particles of polycarboxylates, adsorbed on the active centers of cement grains, form a condensation film of surfactant molecules on their surface. Calculating the Gibbs adsorption isotherm $(\Gamma=f(c))$ and constructing the dependence $\sigma=f(\ln c)$, the maximum adsorption $\Gamma_{\max }=$ $=2.4 \cdot 10^{-6} \mathrm{~mol} / \mathrm{m}^{2}$ is determined, which corresponds to the formation of a solid surface layer in which the molecules adhere tightly one to another. This state is achieved at PCE concentration $c=2.57 \cdot 10^{-5} \mathrm{~mol} / \mathrm{l}$. Further increase in surfactant concentration leads to the formation of micelles, which, in contrast to the asymmetric structures of surfactants, are characterized by a spheroidal structure and are not characterized by surface activity. Therefore, when the concentration increases after the critical concentration of micelles, the surface tension does not change.

The value of maximum adsorption allows us to determine the area occupied by a single PCE molecule on the surface in a saturated adsorption layer [25]:

$$
S_{0}=1 / \Gamma_{\max } N_{A}=1 /\left(2.1 \cdot 10^{-6} \cdot 6.02 \cdot 10^{23}\right)=0.69 \mathrm{~nm}^{2}
$$

where $N_{A}$ is Avogadro's number.

As a result of PCE molecules adsorption on the surface of cement grains, their defloculation occurs, adsorption and immobilized water in the flocculates releases, which leads to the increase in the dispersion medium volume, the decrease in viscosity and the increase in a plasticization effect.

Assuming that the hydrophobic hydrocarbon radical in the saturated monomolecular layer is oriented vertically, and knowing the maximum adsorption, one can calculate the thickness of the polycarboxylate film, which corresponds to the adsorption layer [25]:

$\delta=\Gamma_{\max } \cdot V_{m}=\Gamma_{\max } \cdot M / \rho=2.4 \cdot 10^{-6} \cdot 7000 / 1.12 \cdot 10^{6}=15.0 \cdot 10^{-9} \mathrm{~m}$ where $V_{m}$ is the molar volume of the surfactant, $M$ is the molar mass of the surfactant, $\rho$ is the surfactant density.

Such hydrophobic long branched chains of polycarboxylates create a two-dimensional film with improved structural and mechanical properties, providing the implementation of "steric" (structural-mechanical) effect of Portland cement systems stabilization. 


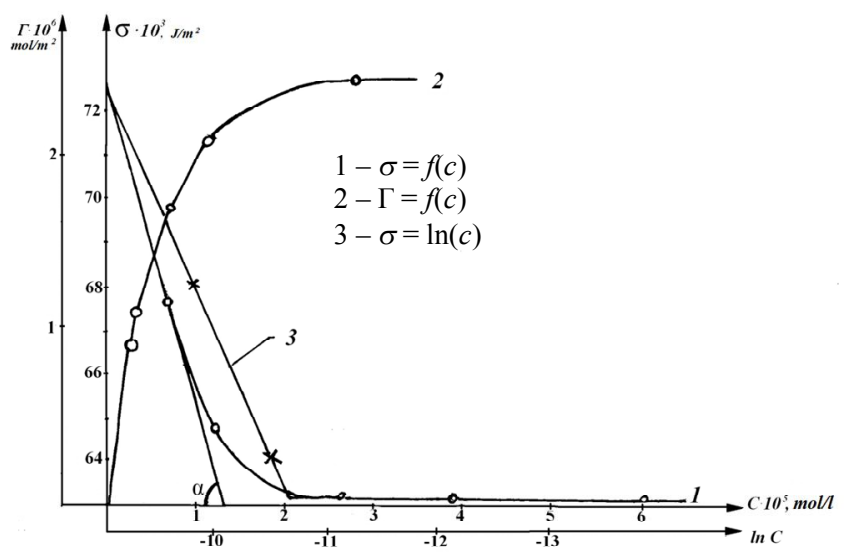

Fig. 2. Isotherms of surface tension and Gibbs adsorption of polycarboxylates

The $\zeta$-potential is an important characteristic of dispersion systems, which determines their stability. In this regard, for the characterization and evaluation of the superplasticizer efficiency and mechanism, we measured the $\zeta$-potential value in cement suspensions without additives and with the addition of PCE (1.0 and $2.5 \mathrm{wt} \%)$. As can be seen from Fig. 3, the $\zeta$-potential of the system without additives is $+27 \mathrm{mV}$. The double electric layer (DEL) of this system is formed by the potential defining ions $\mathrm{Ca}^{2+}$, the charge of which is neutralized by the part of the counterions $\mathrm{OH}^{-}$, forming an adsorption layer.

When introducing polycarboxylates-based modifiers, the $\zeta$-potential of the Portland cement system changes its sign to a negative one. Polycarboxylate anions are characterized by high adsorption capacity and not only compensate the surface potential, but also create an excess charge with a sign of counterion charge, causing the restructuring of DEL. In this case, the adsorption layer is formed by $\mathrm{Ca}^{2+}$ cations and anions of PCE. As a result, the surface tension decreases and repulsion of particles occurs due to the like charges which are concentrated from each phase during their overlap, thus the cement system is stabilized by the forces of electrostatic repulsion.

The use of nanomodifiers in cement systems can greatly affect the charge of cement particles, thus changing not only the state of the system's rheology, but also the nature and rate of hydration processes. Portlandite is the main crystalline product of Portland cement hydration. According to electron microscopy data the basic elements of the crystal structure of alit cement paste in the process of its hardening are hexagonal lamellar crystals, which determine basically the cement technical properties [26]. Structural features of calcium hydroxide crystals determine octahedral portlandite packages. Portlandite layers also act as a matrix for calcium in calcium hydrosilicates for condensation of $\mathrm{SiO}_{4}$ tetrahedrons during the alit phase hydration. The crystalline grate of portlandite is built as the three-layered packages of $\mathrm{HO}-\mathrm{Ca}-\mathrm{OH}$ which are represented as a gigantic two-dimensional molecule, $n$-fold to the portlandite formula. Adhesive power inside the "triple" layers has an ionic character. The relations between neighboring packages are van der Waals ones. The van der Waals bond is much weaker than the ion one, so such "package" structures are characterized by reduced strength in areas which are parallel to the layers (weak cracking and sliding) [27, 28].

The change in the morphology of $\mathrm{Ca}(\mathrm{OH})_{2}$ crystals in the presence of chemical additive modifiers, in particular polycarboxylate superplasticizers, can be controlled by the properties of a cation matrix. Photographs of portlandite cultures grown in an aqueous medium without additives and in the presence of nanomodifiers are represented in Fig. 4. $\mathrm{Ca}(\mathrm{OH})_{2}$ crystals, grown in aqueous medium without additives, have a shape of hexagonal prisms of 5-7 mm height and 2-3 mm faces (Fig. 4a). The increase in dispersion of calcium hydroxide crystals grown in a medium of nano-additives should be noted (Fig. 4b-d).

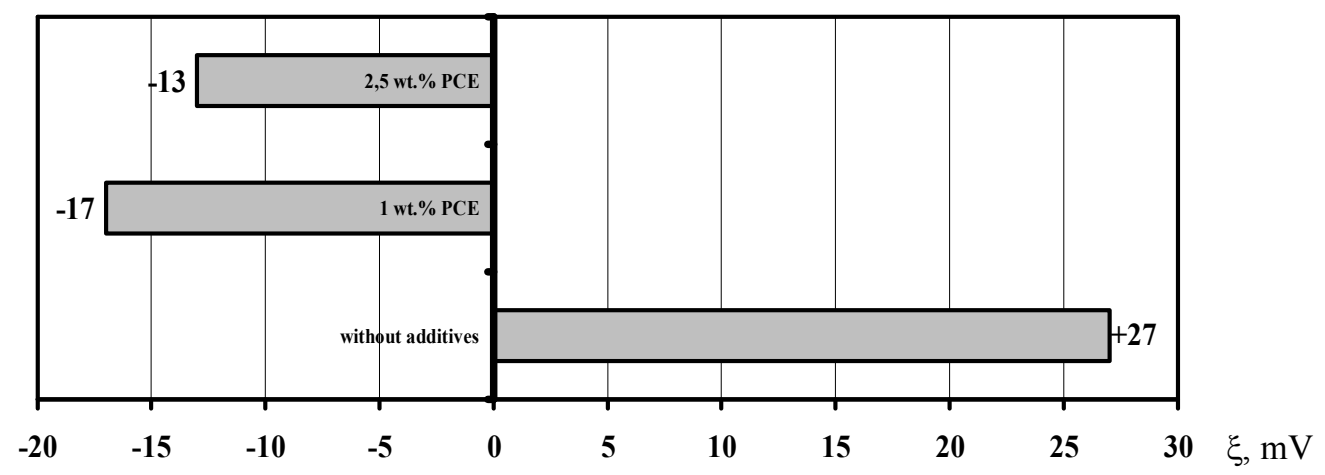

Fig. 3. Influence of polycarboxylates on the change of $\zeta$-potential of Portland cement suspension 


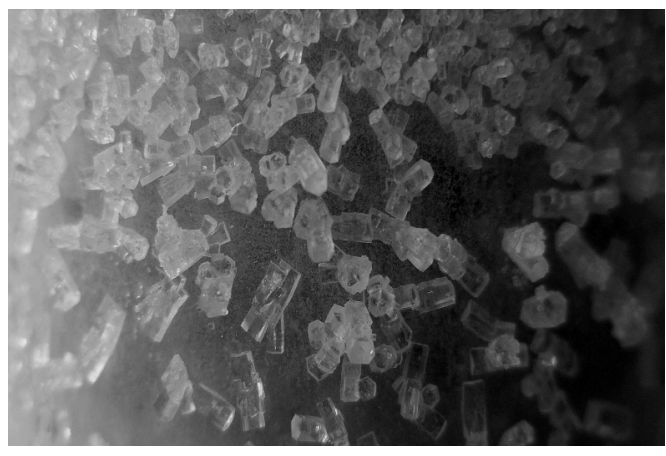

a)

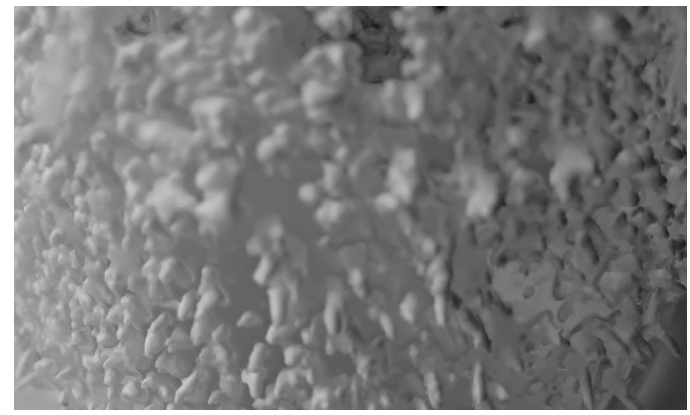

c)

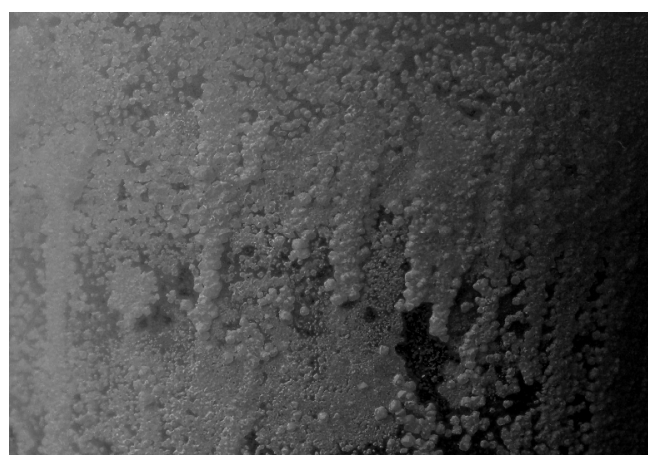

b)

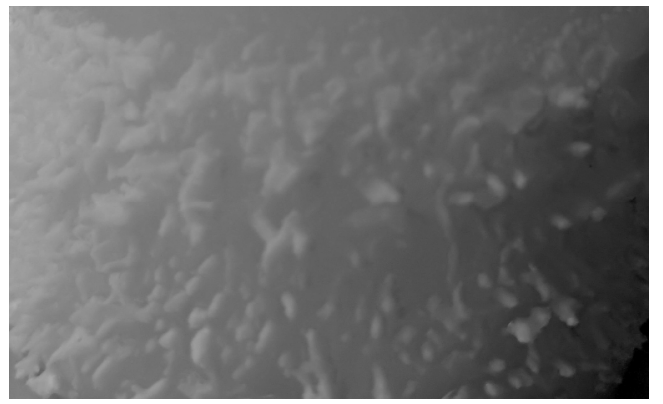

d)

Fig. 4. $\mathrm{Ca}(\mathrm{OH})_{2}$ monocrystals grown in the medium without additives (a); with PCE (b); X-SEED 100 (c) and PCE+X-SEED 100 (d)

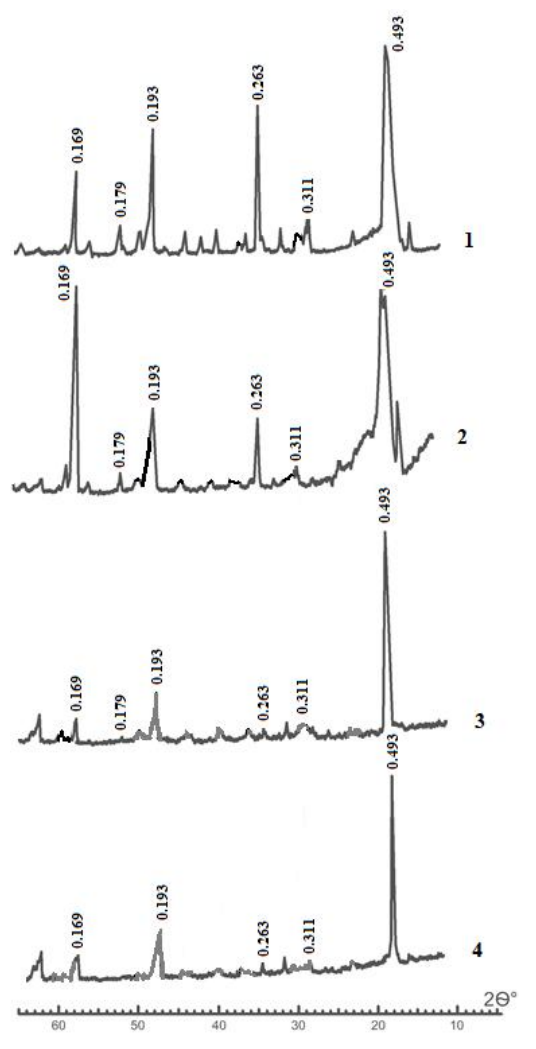

Fig. 5. Difractograms of $\mathrm{Ca}(\mathrm{OH})_{2}$ monocrystals grown in the medium without additives (1); with PCE (2); X-SEED 100 (3) and PCE+X-SEED 100 (4)
X-ray diffraction was used to identify the crystalline phase of the prepared samples and the results are presented in Fig. 5. In all cases a crystalline material was obtained, which matched the $\mathrm{Ca}(\mathrm{OH})_{2}(d / n=0.493$; $0.311 ; 0.263 ; 0.193 ; 0.179 ; 0.169 \mathrm{~nm})$. It is known [27] that on the graphs of pure calcium hydroxide, the intensity of the face line (0001) with $d / n=0.493 \mathrm{~nm}$ is $70-80 \%$ of the intensity of the plane lines (10i11) with $d / n=0.263 \mathrm{~nm}$. This is due to the predominant formation of $\mathrm{Ca}(\mathrm{OH})_{2}$ large crystals. X-ray analysis allowed to reveal the fluctuations of the ratio of the lines $d / n_{0001}=0.43 \mathrm{~nm}$ and $d / n_{10 \overline{1}}=0.263 \mathrm{~nm}$. The intensity of the line $d / n=0.263 \mathrm{~nm}$ of portlandite crystals grown in the PCE medium is reduced to $36 \%$ of the intensity of the line $d / n=0.433 \mathrm{~nm}$. The intensity of the reflexes is connected with the defect of certain positions, isomorphic substitution or the introduction of other atoms.

The SEM images show that particles formed in water were clearly facetted as hexagonal shape crystal size $100 \mu \mathrm{m}$ (Fig. 6a). Introduction of PCE into the system prevents the formation of phase contacts between crystals, which is connected with the appearance of particles on the surface as a result of adsorption of two-dimensional structures consisting of dyfil PCE molecules oriented to the hydrophilic surfaces by polar groups. Formed on the sides with a large surface activity, adsorption layers of polycarboxylates significantly slow down $\mathrm{Ca}(\mathrm{OH})_{2}$ nuclei growth process, causing the increasing of their dispersion. 
The size of $\mathrm{Ca}(\mathrm{OH})_{2}$ crystals is $2-3 \mu \mathrm{m}$. These pellicles delay the rate of crystal growth and affect their shape (Fig. 6b). Particles are slightly elongated in the direction 001 axis which is clearly discernible.

In the presence of highly efficient PCE the surface tension at the phase boundary decreases providing a lower level of fluctuations for the formation of crystal nuclei in a homogeneous nucleation and making possible the formation of a greater number of nuclei. The polycarboxylate superplasticizer is an amphiphilic copolymer that can form micelles in an aqueous solution, this micelle is dynamically stable in an aqueous solution. These micelles work as "pseudonuclei" for the formation of the calcium hydroxide nano-crystal nuclei. Therefore, the nature of the nucleation during $\mathrm{Ca}(\mathrm{OH})_{2}$ crystallization in the medium of PCE is accelerated by the formation of superdispersed crystals.

On the other hand, the influence of organic additives on the nucleation and crystal growth rates and its morphology, and particle size can be caused by a decrease of $\mathrm{Ca}^{2+}$ ion concentrations. The carbonyl functional groups $(-\mathrm{COO})$ could interact with $\mathrm{Ca}^{2+}$ ions effect and form PCE- $\mathrm{Ca}^{2+}$ chelate [29]. In this case polycarboxylate acts as an inducer to attract $\mathrm{Ca}^{2+}$ due to electrostatic forces. The $\mathrm{OH}^{-}$ions interact with the $\mathrm{Ca}^{2+}$ ions of PCE$\mathrm{Ca}^{2+}$ chelate and induce the formation of portlandite particles. PCE still covers the surface of the $\mathrm{Ca}(\mathrm{OH})_{2}$ crystals, the side chains may disperse and stabilize them, resulting in the inhibition of further growth of $\mathrm{Ca}(\mathrm{OH})_{2}$ nanoparticles, which was the reason for smaller size and

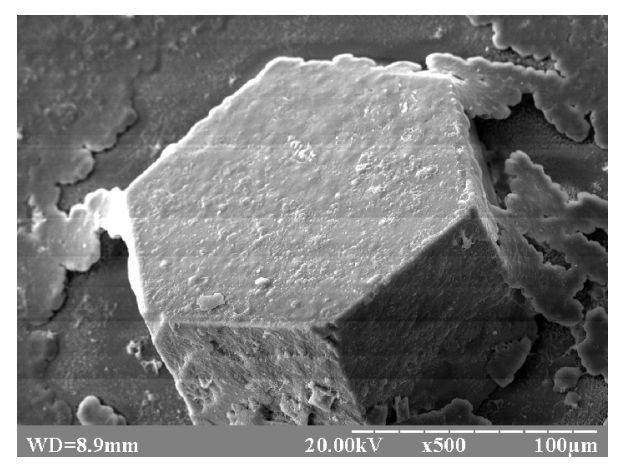

a)

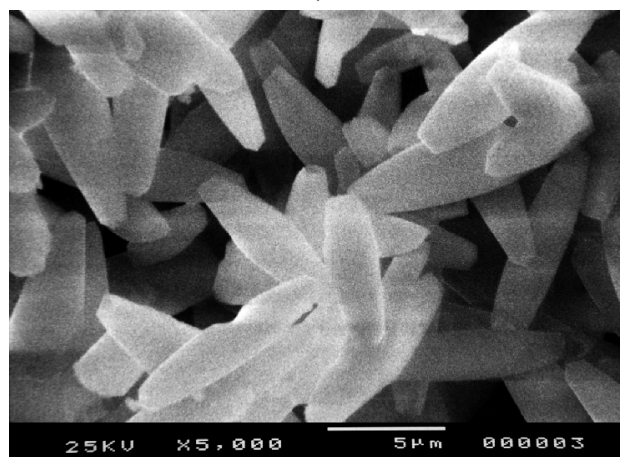

c) uniform distribution of particles. During the crystallization process, polycarboxylate plays two roles: as an inducer and an inhibitor.

The introduction of calcium hydrosilicate nanosized particles (the active centers of crystallization) into a supersaturated solution reduces the activity of nuclei formation, initiates their appearance and promotes their growth. At the same time, the greater the affinity (isomorphism) of the surface with dissolved substance, the less the energy required to form the nuclei on the resulting surfaces of phase boundary. The predominant nucleation rate at the introduction of X-SEED results in the formation of a fine-crystalline product with a weakly expressed crystalline cone-shaped structure containing crystal aggregates and agglomerates of 5-7 $\mu \mathrm{m}$ in size (Fig. 6c).

When the complex nanomodifier PCE + X-SEED is introduced the ontogeny of calcium hydroxide crystals is complicated due to the presence of more ions in the solution. The increase in the ionic strength of the solution causes the supersaturation of the liquid phase, blocks the growth of crystals and provides the avalanche-like appearance of crystallization nuclei, which is accompanied by a decrease in the free energy of the system. This is the reason for the growth of single crystals in the form of shef-like or rosette-like aggregates. These pellicles delay the rate of crystal growth and affect their shape (Fig. 6d), bringing it closer to globular. The size of individual crystals reaches $2-3 \mu \mathrm{m}$.

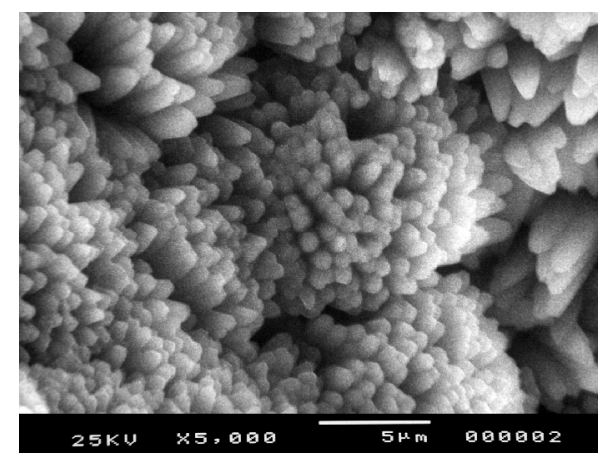

b)

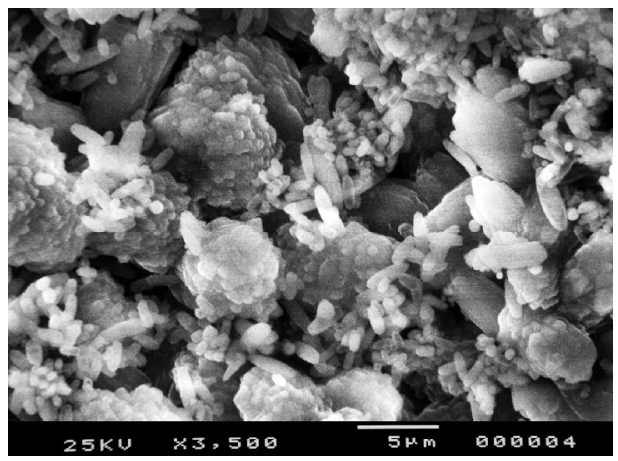

d)

Fig. 6. Microstructure of portlandite monocrystals grown in the medium without additives (a); with PCE (b); X-SEED 100 (c) and PCE+X-SEED 100 (d) 


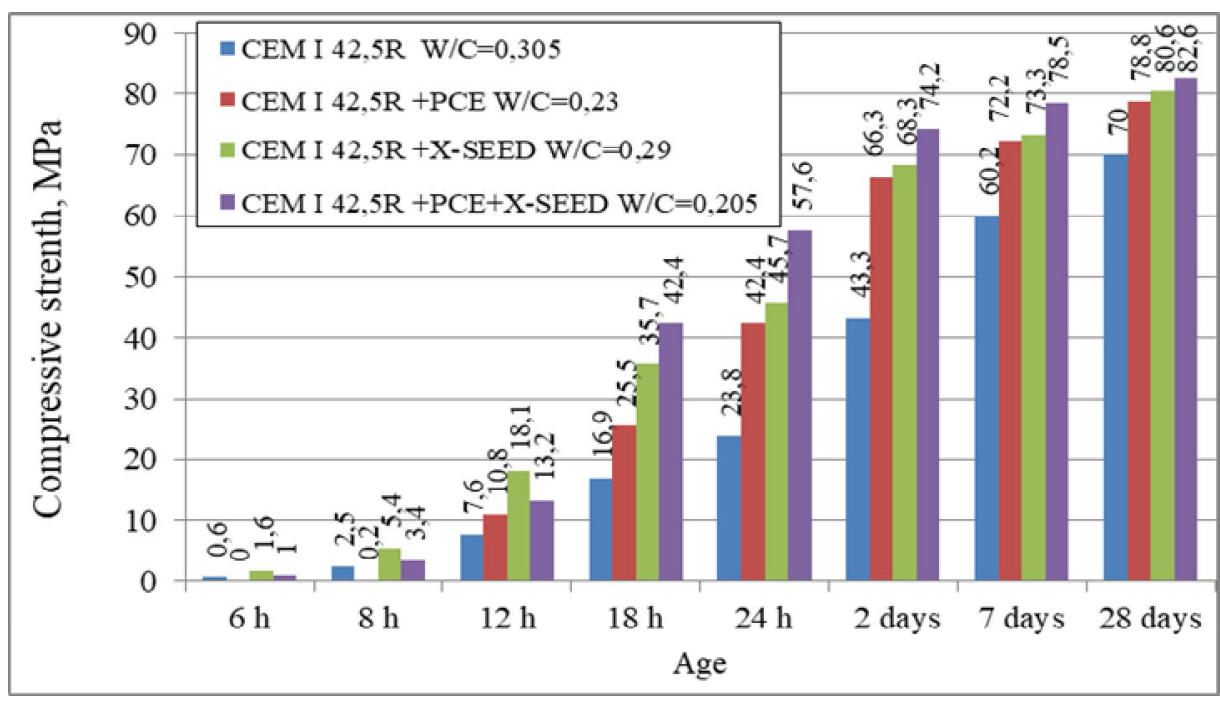

Fig. 7. Effect of nanomodifiers on the strength of Portland cement systems

Nanomodifiers are active components which affect the nucleation and crystallization in cementitious materials and determine the transition of the material from a liquid suspension to a hardened constructive material. The kinetics of hydration and early strength development are closely related to the physical and chemical processes that occur in a liquid phase of a hardening Portland cement system. Portland cement modification by PCE superplastisizer can reduce water consumption by $32.6 \%$ when the same consistency is reached. Significant waterreducing effect is achieved by reducing the surface energy of the system - the decrease in its surface tension by adsorption of surfactant molecules and their definite orientation, which contributes to defloculation and separation of immobilized water, which plays the role of a lubricant. Initial $\mathrm{W} / \mathrm{C}$ determines the concentration of cement particles and the distance between them until the structure formation begins. However, for the paste based on CEM I 42.5R it was found that the introduction of $1.5 \mathrm{wt} \%$ of polycarboxylate with the simultaneous water reduction $(\Delta \mathrm{W} / \mathrm{C}=32.6 \%)$ delays the beginning of setting to $250 \mathrm{~min}$, and its end - up to $490 \mathrm{~min}$, while the same values of the cement paste without additives are 180 and $350 \mathrm{~min}$, respectively. It is caused by the steric effect of polycarboxylate side chains, which makes it impossible to form contacts between the hydration products and delay the formation of the spatial framework up to $8 \mathrm{~h}$. After reaching the critical concentration of nuclei in the interstitial space, an intense structure formation takes place and the strength increases by 1.4 times in $12 \mathrm{~h}$ compared with the paste based on CEM I 42.5R (Fig. 7).

When modifying Portland cement with synthetic nanoparticles C-S-H, an acceleration by 80 min of early structure formation is observed; in the presence of a complex nano-modifier X-SEED+PCE - by $70 \mathrm{~min}$. The acceleration occurs due to the presence of crystallization centers and the creation of an initial dense structure [11]. Synthetic C-S-H nanoparticles contribute to a homogeneous nucleation in the pore solution and form hydrosilica gel (outer product). Nanosized $\mathrm{C}-\mathrm{S}-\mathrm{H}$ phases fill pore space and thus accelerate structure formation and strengthening. So, after $8 \mathrm{~h}$, the strength of the paste modified by X-SEED is higher by 2.2 times compared with the strength of the paste without additives. After $24 \mathrm{~h}$ of hardening, the value of the specific strength of the nanomodified paste $\left(\mathrm{R}_{\mathrm{c} 1} / \mathrm{R}_{\mathrm{c} 28}\right)$ is 0.57 ; and after 2 days $\mathrm{R}_{\mathrm{c} 2} / \mathrm{R}_{\mathrm{c} 28}=0.85$.

The introduction of a complex nanomodifier $\mathrm{PCE}+\mathrm{X}-\mathrm{SEED}$ reduces the negative influence of PCE on the early structure formation of Portland cement and the beginning of setting occurs after $110 \mathrm{~min}$, whereas the period between the beginning and the end of setting is reduced. However, the strength of the cement paste with $\mathrm{PCE}+\mathrm{X}-\mathrm{SEED}$, is lower by $27-34 \%$ compared with the paste modified by X-SEED additive for a period till $12 \mathrm{~h}$. After $18 \mathrm{~h}$ the intensive structure formation takes place and the strength of the Portland cement system with PCE $+X-S E E D$ exceeds the strength of the cement with XSEED by $18.4 \%$. The nano-modified Portland cement system after 2 days is characterized by a specific strength of $\mathrm{R}_{\mathrm{c} 1} / \mathrm{R}_{\mathrm{c} 28}=0.70$ and $\mathrm{R}_{\mathrm{c} 2} / \mathrm{R}_{\mathrm{c} 28}=0.90$, which meets the requirements for extra rapid-hardening systems.

\section{Conclusions}

The use of chemical additives is one of the most rational ways of modifying cement systems at the stage of obtaining a high mobility matrix; it also allows to change the phase composition and microstructure of cement paste 
to provide its strength and durability. It was established that the peculiarities of Portland cement hydration in the presence of polycarboxylates are caused by their high surface activity $(0.9 \mathrm{~J} \cdot \mathrm{m} / \mathrm{mol})$, ability to adsorption modification, electrostatic and steric mechanisms of Portland cement systems defloculation.

The morphological peculiarities of Portland cement monocrystals were studied in the presence of nanomodifiers based on polycarboxylates and $\mathrm{C}-\mathrm{S}-\mathrm{H}$ nanoparticles. We demonstrated the possible ways to control the rates of nucleation and nuclei growth, the conditions for the formation of the granulometric composition of hydrates at the stage of the origin and development of a new phase. Due to the blocking of the active facet growth by adsorption layers of the polycarboxylates (adsorption modification) and the introduction of additional crystallization centers (heterogeneous nucleation), the form of $\mathrm{Ca}(\mathrm{OH})_{2}$ crystals becomes globular and does not exceed 2-3 $\mu \mathrm{m}$. Due to the use of a complex nanomodifier based on polycarboxylate superplasticizer, which provides an increase in the number of nuclei in the early period of hydration with the formation of nanosized $\mathrm{C}-\mathrm{S}-\mathrm{H}$ phases and leads to an increase in the number of contacts, a significant increase in the early strength of Portland cement systems is achieved. The hardening rate of nanomodified Portland cement systems meets the requirements for extra rapid-hardening systems $\left(\mathrm{R}_{\mathrm{cl}} / \mathrm{R}_{\mathrm{c} 28}=0.70\right.$ and $\left.\mathrm{R}_{\mathrm{c} 2} / \mathrm{R}_{\mathrm{c} 28}=0.90\right)$.

\section{References}

[1] Ashani H., Parikh S., Markna J.: Int. J. Nanosci. Nanoeng., 2015, 2, 32.

[2] Czarnecki L.: Przegląd Budowlany, 2011, 1, 40.

[3] Sikora P., Abd Elrahman M., Stephan D.: Nanomater., 2018, 8, 465. https://doi.org/10.3390/nano8070465.

[4] Mendes T., Hotza D., Repette W.: Rev. Adv. Mater. Sci., 2015, 40, 89 .

[5] Gopalakrishnan K., Birgisson B., Taylor P. et al.:

Nanotechnology in Civil Infrastructure: A Paradigm Shift. SpringerVerlag, Berlin Heidelberg 2011. https://doi.org/10.1007/978-3-64216657-0.

[6] Scrivener K., Nonat A.: Cement Concrete Res., 2011, 41, 651. https://doi.org/10.1016/j.cemconres.2011.03.026.

[7] Jo B.-W., Kim C.-H., Tae G. et al.: Constr. Build. Mater., 2007, 21, 1351. https://doi.org/10.1016/j.conbuildmat.2005.12.020.

[8] Sikora P., Horszczaruk E., Cendrowski K. et al.: Nanoscale Research Letters, 2016, 11, 182. https://doi.org/10.1186/s11671016-1401-1

[9] Kotsay G.: Chem. Chem. Technol., 2013, 7, 335.

[10] Kawashima S., Hou P., Corr D. et al.: Cement Concrete Comp., 2013, 36, 8. https://doi.org/10.1016/j.cemconcomp.2012.06.012 [11] Marushchak U., Sanytsky M., Mazurak T. et al.: East Eur. J. Enterpr. Techn., 2016, 6, 50. https://doi.org/10.15587/17294061.2016.84175.
[12] Pozniak O., Sanytsky M., Zavadsky I. et al.: East Eur. J. Enterpr. Techn., 2018, 6, 39. https://doi.org/10.15587/17294061.2018.133594.

[13] Marushchak U., Sanytsky M., Korolko S. et al.: East Eur. J. Enterpr. Techn., 2018, 2/6, 34. https://doi.org/10.15587/17294061.2018.127001.

[14] Schröfl C., Gruber M. et al.: Proceed. $2^{\text {nd }}$ Int. Symposium on Ultra High Performance Concrete. Germany, Kassel 2008, 383.

[15] Plank J., Lei L.: ZKG Int., 2017, 70, 28.

[16] Mohamed E.-S., Hanaa H.: Am. J. Nanomater., 2016, 4, 44. https://doi.org/ 10.12691/ajn-4-2-3.

[17] Plank J., Schönlein M., Kanchanason V.: J. Organomet.

Chem., 2018, 869, 227.

https://doi.org/10.1016/j.jorganchem.2018.02.005.

[18] Konsta-Gdoutos M., Metaxa Z., Shah S.: Cement Concrete Res., 2010, 40, 1052.

https://doi.org/10.1016/j.cemconres.2010.02.015.

[19] Pushkarova K., Sukhanevych M., Marsikh A.: Mater. Sci. Forum, 2016, 865, 6 .

https://doi.org/10.4028/www.scientific.net/MSF.865.

[20] Thomas J., Jennings H., Chen J.: J. Phys. Chem. C, 2009, 113, 4327. https://doi.org/10.1021/jp809811w.

[21] John E., Matschei T., Stephan D.: Cement Concrete Res., 2018, 113, 74. https://doi.org/10.1016/j.cemconres.2018.07.003.

「22] Yakymechko Y., Chekanskyi B.: Chem. Chem. Technol., 2017, 11, 93. https://doi.org/10.23939/chcht11.01.093.

[23] Galmarini S., Bowen P.: Cement Concrete Res., 2016, 81, 16. https://doi.org/10.1016/j.cemconres.2015.11.008.

[24] Pashchenko A., Sanitsky M., Shevchuk G. et al.: Ukr. Khim. Zh., 1990, 56, 794.

[25] Dibrivnyy V., Serheyev V., Van-Chyn-Syan Y.: Kurs

Koloyidnoi Khimii, Intelekt - Zakhid, Lviv 2008.

[26] Sanytsky M.: Proceed. $19^{\text {th }}$ Int. Baustofftagung. Germany, Weimar 2015, 607.

「27] Shpynova L., Ilyukhin V., Sanitskii M.: Neorg. Mater., 1985, 21, 1786.

[28] Sanytsky M., Pozniak O., Soltysik R.: Weimar Gypsum Conference. Germany, Weimar 2011, 135.

[29] Saraya M, Bakr I.: Am. J. Nanotechnol., 2011, 2, 106.

Received: June 22, 2018 / Revised:August 27, 2018 / Accepted: October 22, 2018

\section{ОСОБЛИВОСТІ ПРОЦЕСІВ СТРУКТУРОУТВОРЕННЯ НАНОМОДИФІКОВАНИХ ПОРТЛАНДЦЕМЕНТНИХ СИСТЕМ}

Анотація. Показано, щзо регулювання процесів гідратаиії на наноструктурному рівні внаслідок адсорбиійного модифікування продуктів гідратаиії полікарбоксилатом та введення нанорозмірних C-S-H-частинок сприяе однорідному розподілу твердої фази в структурі иементного каменю на мікро- та нанорівнях, збільшенню кількості контактів між гідратами, забезпечує швидке формування структури та синтез міцності портландиементної системи.

Ключові слова: наномодифікування, портландцемент, полікарбоксилатний суперпластифікатор, гідратаичя, адсорбиійне модифікування, портландит. 